\title{
The Role of Angiopoietin-1 in Kidney Disease
}

\author{
Won Kim, M.D.
}

\author{
Department of Internal Medicine, Chonbuk National University Medical School, Jeonju, Korea
}

\begin{abstract}
Injury to the renal microvasculature and inflammatory process may be major factors in the progression of renal disease, therefore, protection of the renal endothelial cell and regulation of inflammatory process may be an important therapeutic target of renal disease. Thus, we evaluated the protective effect of cartilage oligomeric matrix protein-angiopoietin-1 (COMP-Ang1) in unilateral ureteral obstruction (UUO)-induced renal fibrosis, cyclosporine A (CsA)-induced renal injury, and the diabetic nephropathy model. In the UUO model, morphologic examination indicated less tubular injury and tubulointerstitial fibrosis in mice that received COMP-Ang1 compared to vehicle-treated mice. Interstitial type I collagen, myofibroblast accumulation, renal surface microvasculature and renal blood flow were higher after treatment with COMP-Ang1 compared to vehicle-treated mice. COMP-Ang1 treatment decreased monocyte/macrophage infiltration, tissue levels of transforming growth factor $\beta 1$, and Smad 2/3 phosphorylation and increased Smad 7 in the obstructed kidney. In CsA-induced renal injury, histologic examination showed significantly decreased CsAinduced tubular damage and tubulointerstitial fibrosis in COMP-Ang1 treated mice. COMP-Ang1 administration also decreased increased macrophage infiltration, adhesion molecule expression, TGF- $\beta 1$, and Smad 2/3 levels in CsA-treated kidneys, while increasing Smad 7 levels. Laser-Doppler sonographic findings and endothelial factor VIII staining revealed that COMP-Ang1 had a preservative effect on peritubular vasculature. In the diabetic nephropathy model, COMP-Ang1 reduced albuminuria and decreased mesangial expansion, thickening of the glomerular basement membrane and podocyte foot process broadening and effacement. COMP-Ang1 may delay the fibrotic changes in the kidney of diabetic $d b / d b$ mice through its antiinflammatory or metabolic effects. In conclusion, COMP-Ang1 may be an endothelium-specific and antiinflammatory therapeutic modality in fibrotic renal disease.
\end{abstract}

Key Words : angiopoietin-1; kidney; endothelial cells

\section{Introduction}

Angiopoietins are a family of growth factors which act on the Tie receptor on endothelial cells. The angiopoietin family consists of 4 angiopoietins, i.e., angiopoietin-1 (Ang1), angiopoietin-2 (Ang2), angiopoietin-3 (Ang3), and angiopoietin-4 (Ang4) ${ }^{1-3)}$. Ang1 is known as an angiogenic factor ${ }^{4}$, however, the function of Ang2, Ang3 and

Received January 2, 2008. Accepted March 4, 2008.

Corresponding author: Won Kim, M.D.

Department of Internal Medicine, Chonbuk National University

Medical School, 634-18, Keumam-dong, Jeonju, 560-180, Korea

Tel : +82-63-250-1651, Fax : +82-63-254-1609

E-mail : kwon@chonbuk.ac.kr
Ang4 is not well known. Angiopoietins' receptor system consists of two receptor tyrosine kinases, Tie1 and Tie2. The Tie receptors are exclusively expressed by endothelial cells and hematopoietic cells ${ }^{5)}$. It has been also reported that Tie 2 is also expressed in macrophages, eosinophils, and hematopoietic stem cells ${ }^{5,6}$. Although Tie1 and Tie2 share a similar structure consisting of an extracellular domain with $33 \%$ similarity and an intracellular tyrosine kinase domain with $76 \%$ similarity, the exact role of Tie1 is not well known ${ }^{7)}$. Ang1 and Ang2 bind to the same site in Tie2 with similar affinities. Ang1 is a widely expressed ligand for the Tie 2 tyrosine kinase receptor that 
is expressed on endothelial cells, and it regulates vascular growth, development, maturation, and permeability ${ }^{8,9)}$. Ang1-induced Tie2 phosphorylation in endothelial cells can activate the protein kinase B/Akt pathway that conducts endothelial survival ${ }^{10-12)}$. Although Ang1 is known as an angiogenic factor, it has been also demonstrated that Ang1 has an anti-inflammatory effect ${ }^{13,14)}$. Although the exact role of Ang2 is not well known, it has been reported that Ang2 functions as an antagonist ligand of Tie $2^{15)}$. Ang1 has potential therapeutic applications in inducing angiogenesis, enhancing endothelial cells survival, and preventing vascular leakage ${ }^{12,16-20)}$ (Fig. 1).

In this section, I focus on the therapeutic effect of Ang1 in kidney disease

\section{Angiopoietin-1 and Tie2 expression in kidney}

Ang1 is also associated with physiologic or pathophysiologic conditions in the kidney ${ }^{21)}$. In kidney development, Tie2 is detected in capillaries of the nephrogenic cortex, glomerular tufts, cortical interstitium, and medulla including vessels in the vasa recta $^{22,23)}$. Thus, Ang1 and Tie2 play roles in the maturation of glomeruli and the vasa rectae. Ang1 protein is detected in podocytes in normal glomeruli and was highly expressed in podocyte foot processes ${ }^{24)}$. Tie2 has been demonstrated on glomerular capillary endothelial cells and peritubular capillary endothelial cells ${ }^{23)}$. Thus, circulating Ang1 may have an effect on renal Tie 2 in the endothelial cell and renal Ang1 may also have paracrine effect on renal Tie $2^{25,26)}$.

Disturbance of endothelial integrity in the kidney may cause a reduction in glomerular filtration rate or proteinuria. Ang1 in the glomerulus or renal epithelial cells may have a role in maintenance of the glomerular or peritubular endothelium in the kidney. In pathophysiologic conditions, folic acid-induced nephropathy is associated with increased Ang1 protein expression in renal

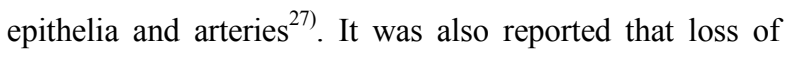
glomerular capillaries during the course of anti-glomerular basement membrane glomerulonephritis in mice was temporally associated with decreases in endothelial survival molecules Ang1 ${ }^{28)}$. Therefore, Ang1 may have an important role in maintenance of normal kidney development of the glomerular or peritubular endothelium and various kidney disease conditions.

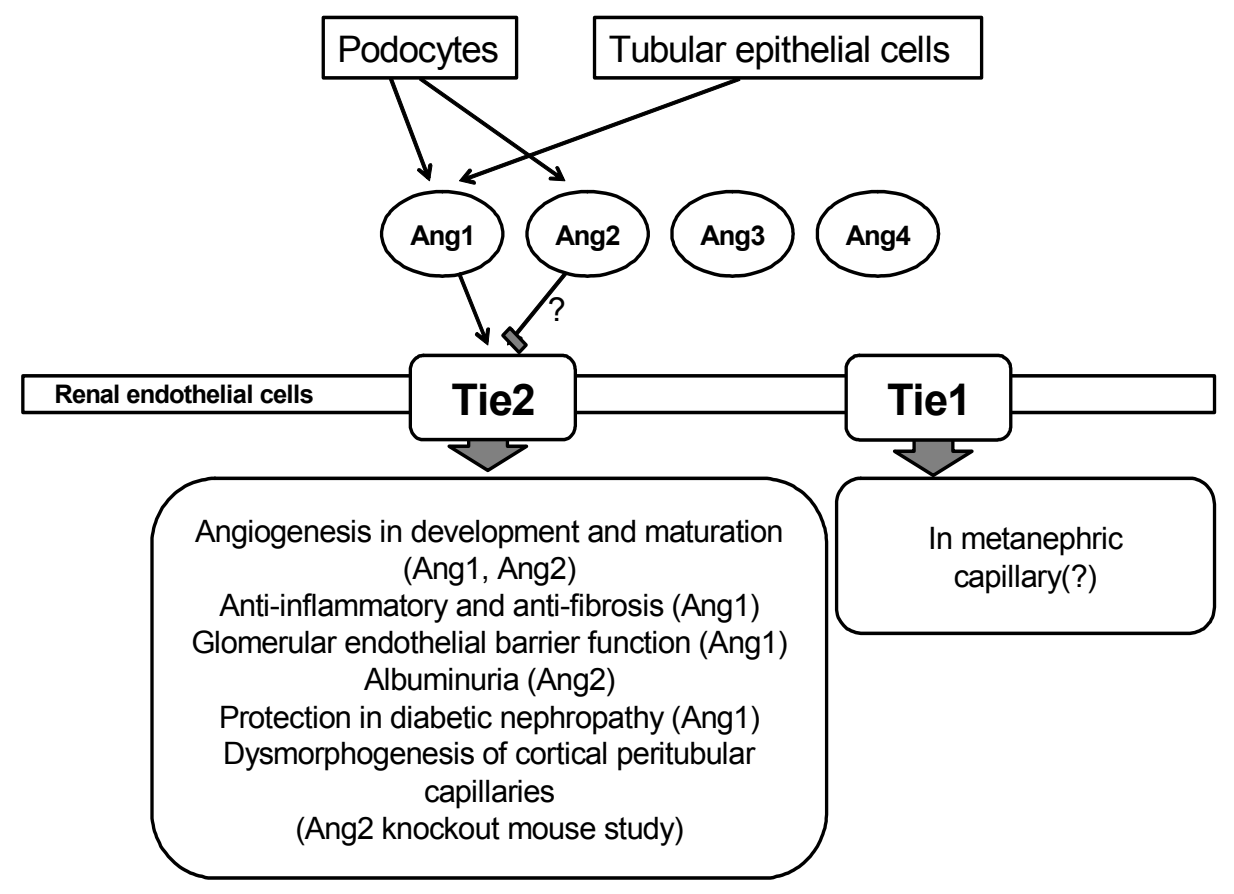

Fig. 1. The function of Angiopoietins (Angs) in kidney development and disease conditions. Tie, angiopoietin receptor. 


\section{Cartilage oligomeric matrix protein-angiopoietin-1 in renal fibrosis}

Most forms of chronic kidney disease finally progress to interstitial fibrosis. The severity of tubulointerstitial changes is the best indicator of the progression of renal dysfunction $^{29,30)}$. Renal tubulointerstitial fibrosis is an important feature in unilateral ureteral obstruction (UUO). In humans, chronic and acute ureteral obstruction can occur in various clinical situations such as ureteral stone or ureteral carcinoma. Injury to the renal microvasculature and inflammatory condition may be major factors in the process of kidney disease $\mathrm{e}^{31)}$. In particular, injury to the peritubular capillary endothelium of the kidney may be a factor in tubulointerstitial disease ${ }^{32-34)}$. It has been reported that impaired angiogenesis may occur in the diseased kidney and can contribute to renal scarring ${ }^{33)}$. Renal ischemia that is caused by vascular obliteration can be a major contributor to renal scarring. Therefore, endothelial cells play an important role in renal disease progression in the unilateral ureteral obstructed kidney. Because renal microvasculature injury involves a critical process in renal fibrosis, a growth factor or cytokine with an endothelial protective or angiogenic effect may have a protective role in renal fibrosis in the UUO model ${ }^{35-37)}$.

Recently, a variant of Ang1, cartilage oligomeric matrix protein (COMP)-Ang1 was recently developed. COMPAng1 is soluble and more potent than native Ang1 in phosphorylating Tie2 and signaling via Akt in primary cultured endothelial cells ${ }^{13,38)}$. Thus, I evaluated the protective effect of COMP-Ang1 in the UUO-induced renal fibrosis $\operatorname{model}^{39)}$.

In the UUO model, COMP-Ang1 preserved the renal platelet-endothelial cell adhesion molecule-1- and Tie2positive endothelial cell. Morphologic examination demonstrated less tubular injury and renal interstitial fibrosis in mice that received COMP-Ang1 than in vehicle-treated mice. Type I collagen and myofibroblast accumulation were significantly decreased by COMP-Ang1 treatment. COMP-Ang1 stimulated Tie2 and Akt phosphorylation in ureteral obstructed kidneys. Renal surface microvascula- ture and renal blood flow were higher after treatment with COMP-Ang1 than in vehicle-treated mice. COMP-Ang1 treatment suppressed monocyte/macrophage infiltration, tissue levels of transforming growth factor $\beta 1$ (TGF- $\beta 1$ ), and Smad 2/3 phosphorylation and increased Smad 7 in the obstructed kidney. These results suggest that COMPAng1 treatment can prevent the progression of renal fibrosis in UUO.

\section{Cartilage oligomeric matrix protein-angiopoietin-1 in diabetic nephropathy model}

Inflammatory processes have been recently seen as the important factor in the pathogenesis of diabetic nephropathy. In this study, $d b / d b$ mice were treated with adenovirus expressing either COMP-Ang1 or Lac ${ }^{40)}$. To evaluate histology, inflammatory, metabolic, and fibrotic parameters and signalling pathways, we used diabetic nephropathy model.

COMP-Ang1 reduced albuminuria in 24 hour urine analysis and decreased mesangial expansion, thickening of the glomerular basement membrane, and podocyte foot process broadening and effacement in histologic examination. COMP-Ang1 decreased both kidney expression of the adhesion molecule and the number of $f 4 / 80$-positive macrophage infiltration in diabetic $d b / d b$ mice. In addition, COMP-Ang1 significantly decreased fasting blood glucose level, epididymal fat weight to body weight ratio, and epididymal adipocyte size in diabetic $\mathrm{db} / \mathrm{db}$ mice. COMPAng1 also ameliorated the fibrotic process in the kidney of diabetic $d b / d b$ mice through its anti-inflammatory and metabolic effects. COMP-Ang1 suppressed renal levels of TGF- $\beta 1$, a-smooth muscle actin, fibronectin, as well as Smad 2/3, but increased Smad 7. In human umbilical vein endothelial cells, COMP-Ang1 treatment decreased high glucose- induced nuclear factor- $\kappa \mathrm{B}(\mathrm{NF}-\kappa \mathrm{B})$ activation. COMP-Ang1 mediated inhibition of increased NF- $\kappa \mathrm{B}-$ DNA binding activity in nuclear extracts from human umbilical vein endothelial cells grown in high glucose was significantly blocked by soluble Tie2 receptor-Fc. The side effect of COMP-Ang1 is not well known. However, there are several conditions associated with COMP-Ang1 such 
as slight increased redness in the nose and increased vascular density in the trachea. These results suggest that COMP-Ang1 ameliorated the fibrotic processes in the kidney of diabetic $d b / d b$ mice through its anti-inflammatory or metabolic effects.

\section{Cartilage oligomeric matrix protein-angiopoietin-1 in cyclosporine-induced renal injury}

In cyclosporine (CsA)-induced renal injury, COMPAng1 significantly decreased CsA-induced tubular damage and tubulointerstitial fibrosis in histologic examination. COMP-Ang1 also reduced the number of macrophage infiltration and expression of adhesion molecules in the CsA-induced renal injury model. COMP-Ang1 administration decreased CsA-induced increase of TGF- $\beta 1$ and Smad $2 / 3$ in kidneys, while increasing Smad 7 levels. Laser-Doppler sonographic findings and endothelial factor VIII staining revealed that COMP-Ang1 had a protective effect on peritubular vasculature and intrarenal hemodynamic alteration in CsA-induced renal injury.

\section{Conclusion}

The protective effect of COMP-Ang1 on of the renal endothelial cell and regulation of inflammatory process may be an important therapeutic target of renal disease. Therefore, COMP-Ang1 may be an endothelium-specific therapeutic modality in various renal diseases.

\section{References}

1) Davis S, Yancopoulos GD: The angiopoietins: Yin and Yang in angiogenesis. Curr Top Microbiol Immunol 237: 173-185, 1999

2) Valenzuela DM, Griffiths JA, Rojas J, Aldrich TH, Jones $\mathrm{PF}$, Zhou H, et al.: Angiopoietins 3 and 4: diverging gene counterparts in mice and humans. Proc Natl Acad Sci U S A 96:1904-1909, 1999

3) Nishimura M, Miki T, Yashima R, Yokoi N, Yano H, Sato $\mathrm{Y}$, et al.: Angiopoietin-3, a novel member of the angiopoietin family. FEBS Lett 448:254-256, 1999

4) Koblizek TI, Weiss C, Yancopoulos GD, Deutsch U, Risau $\mathrm{W}$ : Angiopoietin-1 induces sprouting angiogenesis in vitro. Curr Biol 8:529-532, 1998

5) Kukk E, Wartiovaara U, Gunji Y, Kaukonen J, Buhring HJ, Rappold I, et al.: Analysis of Tie receptor tyrosine kinase in haemopoietic progenitor and leukaemia cells. $\mathrm{Br} \mathrm{J}$
Haematol 98:195-203, 1997

6) Suda T: Function of TIE2/angiopoietin in the angiogenesis and hematopoiesis. Rinsho Ketsueki 41:251-255, 2000

7) Schnurch H, Risau W: Expression of tie-2, a member of a novel family of receptor tyrosine kinases, in the endothelial cell lineage. Development 119:957-968, 1993

8) Breier G, Damert A, Plate KH, Risau W: Angiogenesis in embryos and ischemic diseases. Thromb Haemost 78: 678-683, 1997

9) Breier G: Angiogenesis in embryonic development--a review. Placenta 21(Suppl A):S11-15, 2000

10) Kwak HJ, So JN, Lee SJ, Kim I, Koh GY: Angiopoietin-1 is an apoptosis survival factor for endothelial cells. FEBS Lett 448:249-253, 1999

11) Kwak HJ, Lee SJ, Lee YH, Ryu CH, Koh KN, Choi HY, et al: Angiopoietin-1 inhibits irradiation- and mannitolinduced apoptosis in endothelial cells. Circulation 101: 2317-2324, 2000

12) Kim I, Kim HG, So JN, Kim JH, Kwak HJ, Koh GY: Angiopoietin-1 regulates endothelial cell survival through the phosphatidylinositol 3'-Kinase/Akt signal transduction pathway. Circ Res 86:24-29, 2000

13) Cho CH, Kammerer RA, Lee HJ, Yasunaga K, Kim KT, Choi HH, et al.: Designed angiopoietin-1 variant, COMPAng1, protects against radiation-induced endothelial cell apoptosis. Proc Natl Acad Sci U S A 101:5553-5558, 2004

14) Kim I, Kim HG, Moon SO, Chae SW, So JN, Koh KN, et al.: Angiopoietin-1 induces endothelial cell sprouting through the activation of focal adhesion kinase and plasmin secretion. Circ Res 86:952-959, 2000

15) Maisonpierre PC, Suri C, Jones PF, Bartunkova S, Wiegand SJ, Radziejewski C, et al.: Angiopoietin-2, a natural antagonist for Tie2 that disrupts in vivo angiogenesis. Science 277:55-60, 1997

16) Marti HH, Risau W: Angiogenesis in ischemic disease. Thromb Haemost 82(Suppl 1):44-52, 1999

17) Jain RK, Munn LL: Leaky vessels? Call Ang1! Nat Med 6:131-132, 2000

18) Thurston G, Suri C, Smith K, McClain J, Sato TN, Yancopoulos GD, et al.: Leakage-resistant blood vessels in mice transgenically overexpressing angiopoietin-1. Science 286:2511-2514, 1999

19) Fujikawa K, de Aos Scherpenseel I, Jain SK, Presman E, Christensen RA, Varticovski L: Role of PI 3-kinase in angiopoietin-1-mediated migration and attachment-dependent survival of endothelial cells. Exp Cell Res 253:663672, 1999

20) Thurston G, Rudge JS, Ioffe E, Zhou H, Ross L, Croll SD, et al.: Angiopoietin-1 protects the adult vasculature against plasma leakage. Nat Med 6:460-463, 2000

21) Satchell SC, Mathieson PW: Angiopoietins: microvascular modulators with potential roles in glomerular pathophysiology. J Nephrol 16:168-178, 2003

22) Yuan HT, Suri C, Yancopoulos GD, Woolf AS: Expression of angiopoietin-1, angiopoietin-2, and the Tie-2 receptor 
tyrosine kinase during mouse kidney maturation. J Am Soc Nephrol 10:1722-1736, 1999

23) Woolf AS, Yuan HT: Angiopoietin growth factors and Tie receptor tyrosine kinases in renal vascular development. Pediatr Nephrol 16:177-184, 2001

24) Satchell SC, Harper SJ, Tooke JE, Kerjaschki D, Saleem MA, Mathieson PW: Human podocytes express angiopoietin 1, a potential regulator of glomerular vascular endothelial growth factor. J Am Soc Nephrol 13:544-550, 2002

25) Lu YH, Deng AG, Li N, Song MN, Yang X, Liu JS: Changes in angiopoietin expression in glomeruli involved in glomerulosclerosis in rats with daunorubicin-induced nephrosis. Acta Pharmacol Sin 27:579-587, 2006

26) Satchell SC, Anderson KL, Mathieson PW: Angiopoietin 1 and vascular endothelial growth factor modulate human glomerular endothelial cell barrier properties. J Am Soc Nephrol 15:566-574, 2004

27) Long DA, Woolf AS, Suda T, Yuan HT: Increased renal angiopoietin-1 expression in folic acid-induced nephrotoxicity in mice. J Am Soc Nephrol 12:2721-2731, 2001

28) Yuan HT, Tipping PG, Li XZ, Long DA, Woolf AS: Angiopoietin correlates with glomerular capillary loss in anti-glomerular basement membrane glomerulonephritis. Kidney Int 61:2078-2089, 2002

29) Nath KA: Tubulointerstitial changes as a major determinant in the progression of renal damage. Am J Kidney Dis 20:1-17, 1992

30) Risdon RA, Sloper JC, De Wardener HE: Relationship between renal function and histological changes found in renal-biopsy specimens from patients with persistent glomerular nephritis. Lancet 2:363-366, 1968

31) Bohle A, Mackensen-Haen S, Wehrmann M: Significance of postglomerular capillaries in the pathogenesis of chronic renal failure. Kidney Blood Press Res 19:191-195, 1996
32) Ohashi R, Kitamura H, Yamanaka N: Peritubular capillary injury during the progression of experimental glomerulonephritis in rats. J Am Soc Nephrol 11:47-56, 2000

33) Kang DH, Joly AH, Oh SW, Hugo C, Kerjaschki D, Gordon KL, et al.: Impaired angiogenesis in the remnant kidney model: I. Potential role of vascular endothelial growth factor and thrombospondin-1. J Am Soc Nephrol 12:1434-1447, 2001

34) Ohashi R, Shimizu A, Masuda Y, Kitamura H, Ishizaki M, Sugisaki Y, et al.: Peritubular capillary regression during the progression of experimental obstructive nephropathy. J Am Soc Nephrol 13:1795-1805, 2002

35) Yang J, Liu Y: Blockage of tubular epithelial to myofibroblast transition by hepatocyte growth factor prevents renal interstitial fibrosis. J Am Soc Nephrol 13:96-107, 2002

36) Morrissey J, Hruska K, Guo G, Wang S, Chen Q, Klahr $\mathrm{S}$ : Bone morphogenetic protein-7 improves renal fibrosis and accelerates the return of renal function. $\mathrm{J}$ Am Soc Nephrol 13(Suppl 1):S14-21, 2002

37) Chevalier RL, Klahr S: Therapeutic approaches in obstructive uropathy. Semin Nephrol 18:652-658, 1998

38) Cho CH, Kammerer RA, Lee HJ, Steinmetz MO, Ryu YS, Lee SH, et al.: COMP-Ang1: a designed angiopoietin-1 variant with nonleaky angiogenic activity. Proc Natl Acad Sci U S A 101:5547-5552, 2004

39) Kim W, Moon SO, Lee SY, Jang KY, Cho CH, Koh GY, et al.: COMP-angiopoietin-1 ameliorates renal fibrosis in a unilateral ureteral obstruction model. J Am Soc Nephrol 17:2474-2483, 2006

40) Lee S, Kim W, Moon SO, Sung MJ, Kim DH, Kang KP, et al.: Renoprotective effect of COMP-angiopoietin-1 in $\mathrm{db} / \mathrm{db}$ mice with type 2 diabetes. Nephrol Dial Transplant 22:396-408, 2007 